\title{
TRANSACTIONS
}

OF THE

\section{Royal Academy of Medicine in Ireland.}

\section{MEDICAL SECTION.}

\section{ERYTHEMA MARGINATUM PERSTANS.*}

By J. Magee Finny, M.D. (Dubl.);

Ex-President of the Royal College of Physicians, Ireland; King's Professor of the Practice of Medicine in the School of Physic, Ireland; Clinical Physician to Sir Patrick Dun`s Hospital.

THE case I beg to report to the Academy of Medicine is one of erythema multiforme, which, from its persistence and its peculiarities, is somewhat removed from the ordinary varieties included in the term, and because of these features I have deemed it worthy of being submitted to the members of the Academy, and have designated it under the title of "erythema marginatum perstans." [The patient was exhibited before the Royal Academy of Medicine.]

R. L., a young man, a grocer's assistant, from Banbridge, Co. Down, æt. 2I, of slight build, and weighing 8 st. 7 lbs., was admitted to Sir Patrick Dun's Hospital on October I 3 th, I902, suffering from a skin disease of an erythematous nature which was said to have been present for over three years.

The lad's hair and face and neck were fair, while the

* Read before the Section of Medicine of the Royal Acalemy of Medicine in Ireland, November 2, 1902. 
colour of his body and arms, and of his legs in particular, was of a darker hue-more like what a dark-skinned man might present-with a faint metallic yellow-brown lustre. Standing out from the skin were pink-red coloured elevated lines, and curves and circles and segments and spots, fairly symmetrical in distribution, occupying both the back and front of the thorax, the abdomen, the arms, and the forearms to the back of the wrist, and the nates, thighs and legs as far as the ankles. The palms and soles were free of spots, and the fingers and toes and dorsum of the feet were the only parts exempt. There were a few spots on the back and side of the neck, but the face, scalp, and upper part of the neck were quite free of eruption.

The spots were, some small, quarter-inch in diameter; some large, half-inch ; distinctly raised above the skin to both sight and touch, smooth and without any vesiculation; the colour faded a little on pressure. Again, there were coloured rings and irregular circles of half-inch to one and a half inches in diameter, and many of the spaces enclosed by the raised coloured border were pigmented and covered by the finest scaliness possible, so that they looked as if dusty, and gave the impression that the border was scaly, but closer examination negatived this, as the coloured circumferential border was non-scaly. Again, there were irregular gyrate lines as if formed of two or more broken circles, and, lastly, long lines partly curved and partly straight, which terminated abruptly in clear skin. These latter were mostly present in the adductor and extensor surfaces of the thighs, and near the axillæ over the adjoining pectorals and deltoids.

Further examination revealed the presence of some enlarged glands in the groins and right axilla, and of the right mammary gland. The glands in the neck were normal. A full physical examination showed that all his organs were healthy and all functions were normally discharged, except, 


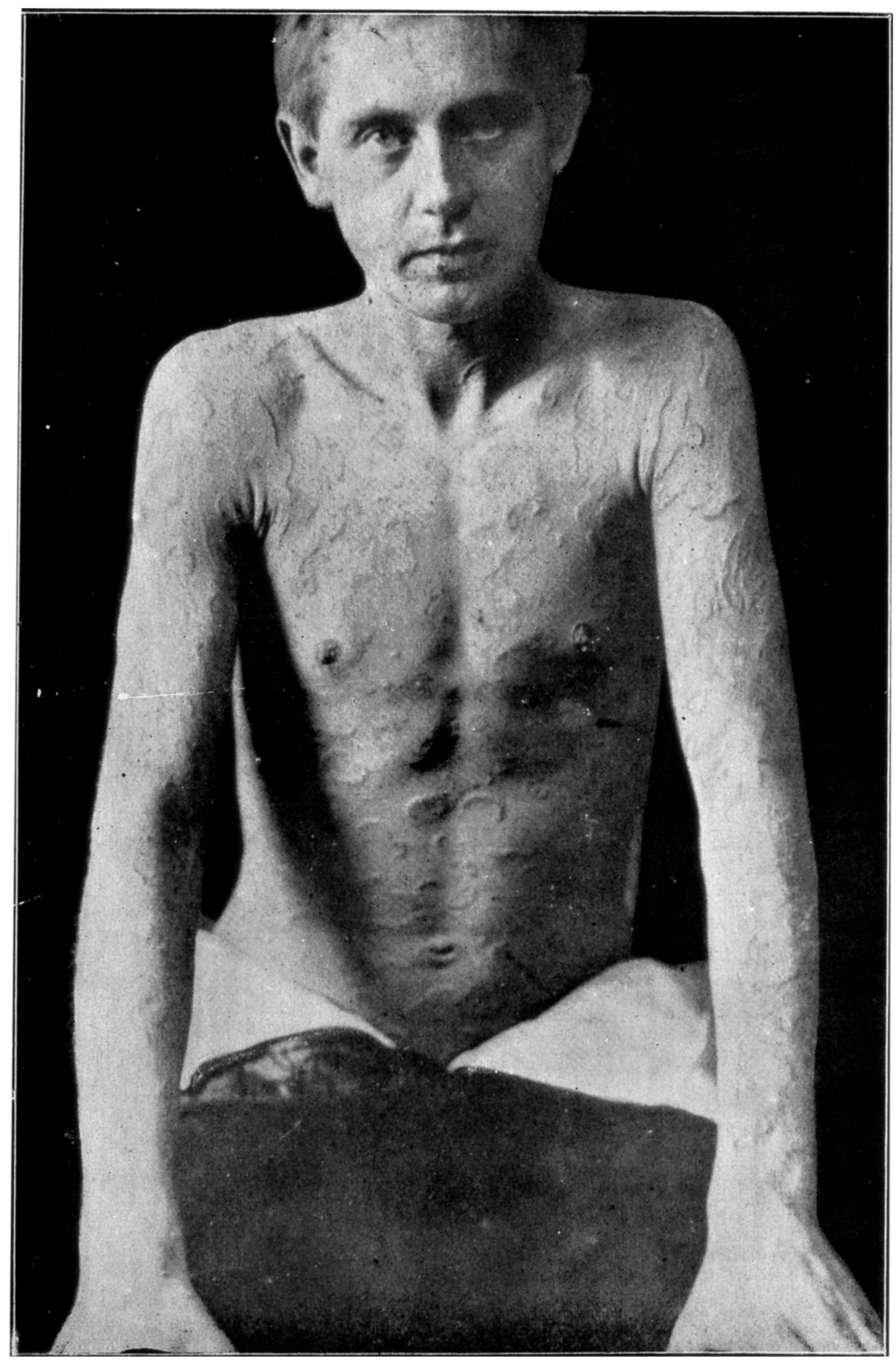

Erythema Marginatum Perstans.

(Circinatum, Gyratum et Marginatum.) 
perhaps, a little indigestion and constipation. There is no evidence of syphilis, and the lad is a total abstainer. His family history is good.

The following personal history and that of the disease was supplied by the patient himself, who is intelligent, and I read it in his own words :-

I first took the disease in August, I899, and, feeling sick, I went home and was attended by the local doctor; on his advice I went into the Banbridge Infirmary on September 9th, I899, and was there only two weeks under treatment, and left seemingly cured. A week had just elapsed when the skin disease came back, and I was readmitted to the infirmary, where I remained about seven weeks, and, though a great deal better when I left, the rash was still out on me. I stayed at home until the end of January, I900, and I then went into the Skin Hospital in Belfast, and remained under treatment for nine weeks. On leaving, the skin rash was better, but not cured, and I remained at home from April to the end of July, using the ointments I had had while in hospital, after which I returned to business. Except for the month of May, Igor, I have been at business until I came to Dublin, October, 1902. In the month of May I had a very bad cold (influenza ?), and during the cold the skin disease came out a great deal more than previously.

During the time at business the skin eruption kept about the same. My legs always were worse than any other part of my body, and if exposed to cold while dressing or undressing would become very hard and of a blackish colour, and they were often swollen about my ankles and even up to the knees. I have had very bad chilblains on my hands the last two winters.

As to my general health, I have not suffered from any bad illness, but $I$ was easily tired, and perspired very readily. My digestion was bad, as after taking food a quantity used to come up, and my mouth had always a dirty, sticky taste in the mornings, and this continued for a long time in spite of care being taken as to my food, \&c. 
The rash or skin disease, which is now on me for over three years, begins something in the form of a hive, and then it spreads in a ring, the centre becoming healthy-looking, while the ring or border is raised and of a red colour ; then one ring meets another, the raised parts blend and spread into all kinds of shapes, and some end in lines either curved or straight. When the inflamed raised parts on my wrists and thighs are much rubbed small watery Dlebs, about the size of a wart, may appear. The skin disease is at times very itchy and especially at night, just like nettle-rash, and I have not been able to resist scratching the spots with my nails sometimes, and have torn them occasionally and made them bleed. The rash has always been worse on my thighs, and legs, and about the knees. My back, shoulders, body, and stomach were also covered with disease ; very few spots ever appeared on my face, scalp or neck, and it is only this year that is has come out so much on my arms and backs of hands. Although it has never gone away altogether since August, r899, it at times was less pronounced, and then again it would return, and though it faded and changed its pattern in one place it would crop up again in another. I do not know any cause for the disease appearing in 1899 in either my habits of living or in my business. I have never had any serious illness, nor am I rheumatic."

To this lucid description I have only to add the results of my own observation while the patient was in hospital.

The eruption, delineated by this painting and these photographs, which latter have been taken by Dr. J. Joly, has been fairly persistent, lasting unchanged for a week or two, and it has been seen to fade in one region while close by to come out afresh. I found the new spots were small papules, and for the purpose of observing their future stages, I enclosed them in a square of aniline ink. In three days they were small circles quarter-inch in diameter, and they were soon seen to reach the enclosing lines and to spread wider and wider beyond them and to form a distinct circle, and then, as the convex edge approached and touched another similarly spreading 
circle a breach occurred at the point of contact and the $E$. annulare or circinatum became $E$. gyratum, the various shapes of which latter depending upon the sizes of the meeting circles; lastly, some of the large gyrate margins, seeming to exhaust themselves, ended in curved lines forming curious devices with terminals abruptly raised-E. marginatum. Except being distinctly raised, they were not at all unlike some tattooing in Egyptian or Hindustani characters. Though I carefully looked for examples of the erythema annulare covered with vesicles-the so-called "herpes iris" -I failed to find any, and in like manner I failed to meet a spot of erythema nodosum.

Recognising that in all probability arsenic and all the usual remedies had been employed on this boy, and with no lasting good effect, I exhibited the use of thyroid extract; at first in doses of 5 grs. twice a day, and later on three times a day. I was led to think of it knowing its remarkable influence on the cutaneous circulation and the stimulation of the cutaneous lymphatics, and hoped that absorption might be affected of the inflammatory exudation which constituted the disease. During its administration the temperature of the extremities was more evenly maintained, and the induration and swelling of the legs reduced; the patient felt more comfortable, and the larger lines and circles have been more or less absorbed on the back and arms, yet the erythematous and indurated lines on the thighs have not improved, and new papules have continued to appear on the back and shoulders, and rings and gyrate patches have recurred on the forearms and spread down on to the back of the hands, while each new crop of papules, \&c., was attended by very well marked itching.

As the results were not sufficiently pronounced, I have therefore discontinued this drug, and have substituted for the present syr. ferr. iodid. and ol. morrhuæ. 
A few words are necessary on the subject of the diagnosis of the disease.

The peculiar appearance of the patches-pink, red, violaceous-which originally came on as an acute attack in $\mathrm{I} 889$, to be followed by similar exacerbations-the patches appearing first of all as small papules circular in form, fading in the centre as they extended peripherally, assuming shapes of irregular curves or festoons, and of long red curved and zigzag lines-this protean character of the eruption makes it take its place under the affection which is termed " erythema multiforme." The only missing members of the family group being the concentric rings possessing variegated coloursred, purple, yellow, and blue-which is designated E. iris, and the solid swellings of the extremities called E. nodosum.

The absence of violent itching and tingling and burning sensations distinguish it from urticaria, which it closely resembles, while the eruption is more pronounced in colour and form, is more persistent, and there is an absence of whea's.

When first seen on the thorax it slightly resembled the circinate and gyrate rash of psoriasis, a drawing of which I submit, but besides its own characteristics, described above, it lacked the two well-marked features of psoriasis, viz., (I) the bleeding points one finds on attempting to scrape away the spots ; and (2) the heaped-up epidermic scales peculiar to the latter disease.

It has nothing in common with eczema-even the variety " eczema papulosum," from which the absence of very severe itching, the large size of the papules, and their irregular shape and form sufficiently distinguish it ; while from "dermatitis herpetiformis" the absence of vesicles and bullæ sufficiently remove it. There were a few vesicles discoverable on one or two of the red lines on the wrists while under hospital supervision, and the patient reports that he had noticed a little moisture to exude occasionally from them when much 
rubbed, but I feel confident this disease is excluded, for while some cases of $D$. herpetiformis have an erythematous and urticarial phase, it is essentially a vesicular or bullous disease, and includes such conditions as "herpes gestationis," hydroa æestiva," or "hydroa vacciniforme," \&c.

The chief resemblance between the two diseases, that is, erythema multiforme and dermatitis herpetiformis, seems to lie in the disposition to group and to extend about the periphery. Dr. Payne showed a case before the Dermatological Society of London in 1898 which he described as " erythema gyratum," but which seemed to have been one of the erythematous stages of dermatitis herpetiformis in the subsequent opinion of himself and Drs. Crocker and Malcolm Morris.

I shall quote the published extract in the "Transactions" (p. I42) as it strongly resembles my case, and it is possible that even in contravention of the above specialists' opinion, Dr. Payne's case was one of erythema multiforme, and not of dermatitis herpetiformis.

"A man, at. 45, presented an eruption, which had lasted sixteen months, and which consisted of erythematous patches varying in size up to some inches in diameter, the larger being distinctly annular or marginate, with a raised, red, somewhat hard margin. The smaller were discoid. Some patches were persistent for a long time (weeks ?), others more transitory, and new patches appeared from time to time. The eruption was generally distributed on the covered parts of the body, but absent from the face and hands. A few spots showed traces of a ruptured vesicle, and the itching was at times very great. The lymph glands all over the body were enlarged and hard, especially in the groin." A subsequent report stated "that under full doses of quinine ( 5 grs. a day) the patient recovered."

Recognising that the case I have reported was out of the ordinary run of cases of erythema, I made search for the 
description of any cases of erythema which could tally with it and consulted all the text-books on skin diseases, including the latest, by Stellwagon (1902), but with little success.* In my search through the volumes of the British Journal of Dermatology I came across two instances, in addition to that of Dr. Payne's, which may be somewhat similar to mine. (a) In Vol. III., p. 24, Dr. Abraham exhibited a woman with erythema perstans affecting the hands, but no notes are recorded. (b) In Vol. IV., Dr. Saville gave the notes of a case of a woman, æt. 35, whom he exhibited to the Society. She had had a first attack five years before, lasting two years, and a second attack, after an interval of nearly three years during which she was quite well. The erythema came out first on the hands and feet, with itching at night, as a slightly raised flat eruption, which in two days became a circle of two inches diameter, the margin was raised, there were no vesicles or scales. Then the rash appeared on the dorsum of the feet, similarly raised, as red circles and segments. Dr. Saville considered it a variety of erythema multiforme, and its nature seemed unknown to the members of the Society present.

I also searched the volumes of the American Journal of Cutaneous and Genito-Urinary Organs, and was so far rewarded by finding one case, and one case only, somewhat closely resembling mine in some of its features. It is recorded by Dr. Lustgarden before the New York Dermatolo-

* Dr. Walter G. Smith has since called my attention to a paper read before the Clinical Society of London by T. Colcott Fox, M.B., November, 1880. In it he details two cases of erythema gyratum perstans in a brother and sister, æt. I9 and 18 , which had lasted, with remissions and quarterly exacerbations, since they were four years of age, with a drawing affixed (lifesize copy is in the Royal Atlas of Rare Skin Diseases). In every feature these cases seem to resemble my case. Steel and cod-liver oil, after a prolonged course, seemed to do them good

Dr. Fox kindly wrote to me on the subject of my paper in January, 1903, and informed me "that his two cases are still going on. The woman has the eruption very slightly now, but the man has the eruption as badly as ever, and always after a free indulgence in alcohol." 
gical Society in I893, Vol. XI., p. Iro, under the name crythema papulatum, vel circinatum figuratum, perstans, et chronicum.

A man, æt. 2I, was struck by a horse on his head, and, two months after having been trephined, an eruption came out on his body and lower extremities in annular or gyrated patches with elevated borders, remaining for weeks and months, and leaving the skin pigmented. New patches were being constantly added, with slight itching and unaccompanied by any other subjective symptom; all medicines employed seemed useless. Dr. Lustgarden considered it a reflex neurosis of traumatic origin.

A passing comment is necessary on the involvement and enlargement of the glands in the groin and in the right axilla, which may be considered a feature of unusual character.

With the exception of Dr. Payne's case (supra) the only allusion to this complication is quoted in Stellwagon's Diseases of the Skin (p. 197) as being Jarish's view that the swelling of the lymphatic glands, especially the cervical, has been sometimes noted in erythema multiforme.

In conclusion, I have to thank the Academy for their patient hearing, and to offer my apologies for having occupied so much of their time in portraying the features of this case. I trust some members present may have seen similar cases, and that they may be able and willing to assist me on the question of treatment.

\section{ADDENDUM.}

The further course of this case after November, I902, was remarkable, for the patient suffered from a severe febrile attack of tonsilitis with diphtheritic-like exudation, which, however, was of the nature of streptococcic and staphylo coccic organisms. The week following vesicles and bullæ formed over all the extremities even to the fingers and toes, 
many of them filled with pus, and some of the bullæ were an inch in diameter; during this illness the erythematous lines and rings became vesicles and pustules, so that if now seen for the first time the symptoms tallied closely with "dermatitis herpetiformis." In six weeks time the eruption had largely disappeared with almost general desquamation and the original erythema seemed for a time to be cured ; but as the patient got stronger and was able to be about, the old disease reappeared with very much the same characters. The patient left hospital in March, r903, and has kept me informed as to his health and state ever since, and on I7th April, I903, wrote: " I am nearly as strong as ever I was. I weigh now ten stone nine pounds, a great increase -over two stone-since I was in hospital. I am sorry I have not a better report to make about my skin. It is much the same as when I wrote to you last." 